\title{
La familia en el escenario de las multipantallas
}

\author{
Carmen Marta Lazo \\ Profesora de Teoría de la Comunicación y de la Información. Universidad San Jorge \\ José Antonio Gabelas Barroso \\ Profesor de Sociología de la Comunicación. Universidad Oberta de Catalunya
}

\section{Resumen:}

El presente artículo se fundamenta en una experiencia pionera en nuestro país en torno a los consumos multipantallas que se producen en las familias. La investigación que presentamos fue realizada en el marco de formación a padres y madres de la Comunidad Autónoma de Aragón. En este estudio exponemos la fase piloto de una macro-investigación que llevaremos a cabo en todo el territorio español. En la investigación realizada pudimos constatar, entre otros aspectos, que la televisión sigue siendo la primera pantalla en la ubicación del hogar y en los consumos y preferencias de las familias.

Palabras clave:

Menores, familia, mediaciones, consumo, recepción, pantallas

Abstract:

The present article is based on a pioneer experience in our country regarding the use of multi-screens in families. The research we present was carried out within a training setting for parents in the Autonomous Region of Aragon. In this study we show the pilot stage of a major research project we shall carry out in the rest of the country. During our research we have been able to confirm, among other aspects, that television is still the first screen in the home and a strong family preference as regards consumption.

Keywords:

Minors, family, mediation, consumption, reception, screens 


\section{Coordenadas espacio-temporales en el consumo audiovisual}

La televisión, las videoconsolas, los dispositivos móviles e Internet forman un universo poblado de conflictos e interacciones, siempre importante en el análisis de estos consumos. Estos escenarios conforman dos espacios, el público y el privado; así como dos tiempos, el tiempo obligado (estudio o trabajo) y el tiempo de ocio. Un dualismo de espacios y de tiempos que establece unos "biorritmos sociales" especialmente en los menores. De lunes a viernes experimentan la obligación (estudio o trabajo); de viernes a domingo, vivencian el tiempo de ocio, que es festivo y alegre. La convivencia con las pantallas se coloca en esa bisagra espacio-temporal, entre el tiempo obligado y el tiempo de ocio, porque ocupa muchos minutos entre semana, pero también dispone de una presencia importante los fines de semana. Por consiguiente, entendemos que será más provechoso hablar de lo que ocurre alrededor de las pantallas, que lo que sucede "dentro de ellas", para lo cual será necesario una mirada que comprenda los contextos de recepción de estos consumos mediáticos, que atienda al conjunto de interacciones entre pantallas y espectadores o jugadores, así como a las múltiples mediaciones que se producen entre los medios y los propios consumidores que forman la célula familiar.

Afirma Lazzarini (2006) que a lo largo del siglo pasado diferentes disciplinas, capitaneadas por el pensamiento sistémico, proponen una visión del mundo desde la totalidad. Esta nueva visión, llamada holística o ecológica, no se centra en los componentes básicos, contempla el universo como un conjunto de relaciones y conexiones entre los seres humanos, la sociedad y la naturaleza. La salud, en esta visión integral, no se reduce a un único aspecto dominante, sino que se concibe como resultado de las relaciones y dependencias recíprocas de varios fenómenos: físicos, biológicos, psicológicos, sociales y culturales. El hombre no es concebido como entidad separada del medio en el que vive, es una parte interdependiente de una totalidad.

Desde esta concepción holística de salud (Marta Lazo y Gabelas Barroso, 2007) entendemos que la educación para el consumo es uno de los factores claves en la educación para la salud. Los menores mantienen hoy una estrecha y continua convivencia con las diferentes pantallas (televisión y cine, Internet, videoconsolas, dispositivos móviles) que conforman un paisaje y un "hábitat de valores" muy cercano y significativo. Indica Trejo (2006: 101) que "los jóvenes de hoy nacieron cuando la difusión de señales de televisivas por satélite ya eran una realidad, saben que se puede cruzar el Atlántico en un vuelo de unas cuantas horas, han visto más cine en televisión y en vídeo que en las salas tradicionales y no se asombran con Internet porque han crecido junta a ella, frecuentan espacios de chat, emplean el correo electrónico y usan programas de navegación en la Red de redes con habilidad...”.

$110 \mid n^{\circ} 7$ | doxa.comunicación 


\section{La familia como marco de pertenencia y referencia}

Los padres y madres son una pieza clave en el seguimiento que sus hijos destinan al consumo multipantallas. El referente que los más pequeños tengan supone un aliciente para tender a unos modelos de consumos más o menos permisivos, restrictivos o equilibrados. No sólo son importantes los parámetros temporales que los progenitores o tutores concedan a sus hijos. Sólo el hecho de dejarles ver, jugar, utilizar o navegar menos o más horas no significa que sus usos sean más saludables. El factor principal gravita en la forma en la que se les orienta. Un consumo compartido sirve para enriquecer el uso que el niño o joven hace de cada pantalla, con las pautas necesarias para saber discriminar aquellos contenidos que no resultan aptos para su edad, la respuesta respecto a aquello que no llegan a comprender o el diálogo abierto de las interpretaciones que cada uno otorga a los mensajes, así como la planificación de tiempos para vivir con variedad, autonomía e inteligencia el ocio.

La relación unidireccional "sujeto-pantalla" pasa a adquirir un nuevo estrato en el que las dimensiones y perspectivas que aporte el padre o la madre pueden ayudarle a encontrar otras esferas de significado. Los flujos de información que le ofrezca una presencia adulta no tienen un mero valor de control con connotaciones negativas, por el simple hecho de "no dejar ver o hacer". Aquello que podría entenderse por las mentes en formación como una intromisión a su voluntad de elegir puede convertirse en el aliciente de que sus padres se preocupen por aquello que les gusta y quieran compartir esos tiempos y espacios de consumo y conversación.

El sano conocimiento de los gustos, intereses y motivaciones por parte de los padres será un motor en la guía hacia la construcción de sus hijos. Fomentar la autonomía, el criterio propio frente o en consonancia con los del resto, es decir la asertividad; el saber argumentar matices por los que la opinión en ciertos aspectos no sea mimética a la de su grupo depende en gran medida del aprendizaje que reciba de sus padres, así como de los modelos de consumos que se establezcan en la dinámica familiar. El hecho de prestar atención a los productos que gustan a los hijos supone un punto de partida "sine qua non" para enrolarse en la irrenunciable función paterna de formación. El respeto será pieza clave para empatizar con seres que pertenecen a una generación distinta y que entienden la realidad bajo unos parámetros que una mente adulta comprende y acepta, en ocasiones, de otra manera.

Las nuevas estructuras sociales, sus modelos económicos, de producción y consumo, afectan a la manera en la que los padres se integran en el uso y consumo que sus hijos hacen de las pantallas. La disponibilidad de tiempo es uno de los "handicaps" más sobresalientes. Esto, unido a la falta de recursos por parte de los padres para manejar estrategias y procedimientos de intervención y negociación debido a sus escasas ha- 
bilidades, conocimiento o preparación, supone un obstáculo para que su mediación sea constructiva, derivando en normativas erróneas, enfrentamientos innecesarios, permisividad u omisiones.

En la investigación que presentamos, tratamos de dilucidar si son tales los límites, cuáles son las formas en las que los padres intervienen, si les preocupa o no el consumo que hacen sus hijos, si participan con ellos en los diferentes visionados, juegos y usos, si existen pautas de orientación y consumo, si les advierten de los perjuicios que hay detrás de las pantallas y potencian los beneficios, si conocen los consumos y usos audiovisuales que sus hijos tienen y disfrutan, cuáles son sus gustos y preferencias ...

En la infancia, esta interacción niños-familia es más sencilla en su planificación (distribución de tiempos para ver la televisión, jugar a la videoconsola, utilizar Internet) y más sencilla en sus mediaciones (conversar con los hijos sobre los programas, usos y consumos de pantallas que arrastran el interés de los vástagos y son motivo para el diálogo, la discriminación y el análisis).

Es en la adolescencia cuando el control y el seguimiento de los gustos y preferencias de sus hijos, así como el tiempo que dedican a cada pantalla, son más complejos y difíciles. La migración que se produce de la pantalla doméstica (televisión), a la pantalla global (Internet) complica el seguimiento de los gustos, gratificaciones y consumos del adolescente. Éstos otorgan una especial importancia a su grupo de iguales (amigos o compañeros), a dejarse llevar por lo que éstos proponen resulta muy tentador y alentador; los usos y el visionados prohibidos en la propia casa se convierten en objeto del deseo así como el consumo y la interacción en las conversaciones y comentarios, dentro de las casas de los amigos o lugares públicos como los ciber.

El contexto de la mediaciones se produce en un conjunto de recepciones mediáticas, de complejo proceso, en el que no sólo intervienen los engranajes sociales y mecanismos cognitivos y emocionales del niño o joven receptor, sino también un proceso de "distanciamiento", que estos sujetos receptores aceptan o rechazan, soportan o negocian, y al mismo tiempo definen. Como indica Elizalde (2007: 76), "el distanciamiento es una categoría construida sobre la base de datos cualitativos y compuesta con varias dimensiones; las dimensiones marcan el modo en que los receptores -niños, jóvenes, adultos- establecen relaciones de más o menos implicación (emocional, cognoscitiva, social), con todos los medios en general y con cada uno en particular". Esto es, el distanciamiento es un factor primordial de la recepción y de las mediaciones que genera unas relaciones sociales con los medios, y establece un pautado social entre los miembros que conforman la estructura familiar. Este factor permite comprender el propio consumo de pantallas pues contiene la historia de los sujetos receptores; de sus contextos (familiares, sociales y culturales); su naturaleza receptiva (en su atención, interpretación, reinterpretación y valoración); así como las estructuras industriales de los medios y sus mecanismos de producción, distribución y exhibición. 
Las modas que instauran los medios y nuevas tecnologías se contagian de manera viral a partir de que los grupos de escolares las acepten como propias. Por este motivo, es interesante que los padres conozcan los motivos por los que sus hijos entran en la espiral de necesidad de pertenencia a un grupo para no sentirse aislados o desplazados. Cuando los esquemas adultos que le proponen sus padres y los que le plantean sus amigos son distintos, los chicos pueden caer en un conflicto intentando adivinar a cuáles se acogen, decantándose generalmente por aquellos que le ofrecen sus iguales en edad. Esta situación de conflicto no sólo afecta a los menores, también a los padres. Sin embargo, crecer no es fácil, ni cómodo, tampoco para los hijos. Entre los diferentes factores que afectan al conflictivo crecimiento de los niños y jóvenes, también hay que tener en cuenta la inmersión en la fenomenología de las pantallas.

\section{Contexto de la investigación realizada con padres y madres aplicada a la dieta de pantallas en el en- torno del hogar ${ }^{1}$}

\subsection{Diseño muestral}

La muestra seleccionada se compone de un total de 127 padres y madres repartidos en 14 puntos de muestro en el territorio aragonés. Nuestro objetivo consiste en analizar cuáles son las tendencias en el uso y consumo de medios de comunicación y nuevas tecnologías en el seno de la Comunidad Aragonesa. En concreto, para analizar de qué modo los padres perciben el consumo multipantallas de sus hijos.

Los puntos de muestro fueron los siguientes:

- Hábitat urbano (Zaragoza y Huesca capital).

- Hábitat rural (pueblos de cada provincia: Aniñón, Sástago, Muel, Fuentes de Ebro y Ariza en Zaragoza; Barbastro y Tardienta en Huesca).

\footnotetext{
${ }^{1}$ Los resultados aportados en este epígrafe se fundamentan en la investigación "Consumos y mediaciones de familias y pantallas. Nuevos modelos y propuestas de convivencia”, realizada por Gabelas, J. A. y Marta, C. (2008), elaborada en el marco del Programa “Pantallas sanas" de la Dirección General de Salud Pública del Gobierno de Aragón.
} 
Figura 1. Puntos de muestreo

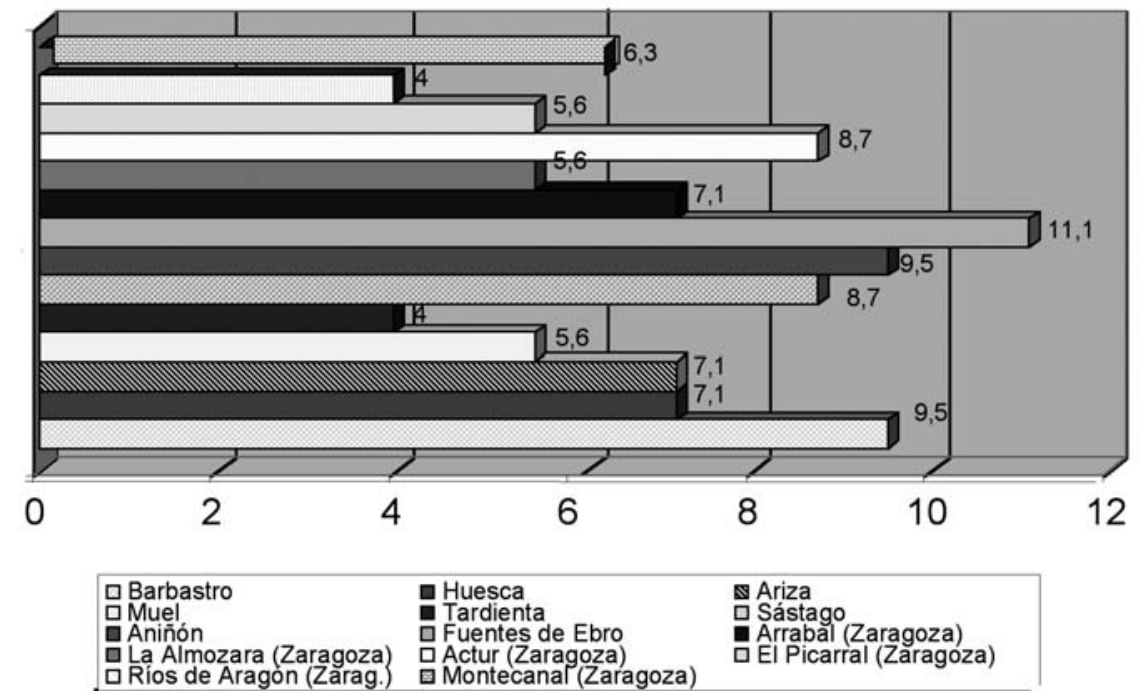

Fuente: Elaboración propia

La muestra, de carácter accesible y estratégica, fue configurada a partir de las AMPAS que solicitaron en el curso 2006/07 el curso "Pantallas sanas". Para ello contamos con la valiosa colaboración de la FAPAR (Federación de Asociaciones de Padres de Aragón). En este sentido, cabe indicar que las familias encuestadas responden al perfil de lo que podríamos denominar "padres y madres sensibilizados" con el potencial socializador que ejercen las pantallas en la familia de modo general, y en sus hijos de modo particular, dado que todos estos padres asistieron a una conferencia para aprender a convivir con las pantallas y disponer de criterios y estrategias de consumo y mediación. No obstante, también precisamos que la encuesta siempre se realizó antes de impartir la conferencia. Por consiguiente, los resultados que exponemos hay que interpretarlos desde esta perspectiva.

\section{Análisis de resultados de la investigación}

\subsection{Equipos y servicios en el entorno doméstico}

Los equipos más implantados en el hogar son el vídeo (97,6\%), la telefonía móvil (94,4\%) y el equipo de música $(90,5 \%)$. El ordenador también se ubica entre los preferentes $(87,4 \%)$, con Internet como aplicación

$114 \mid n^{\circ} 7$ | doxa.comunicación 
(65,3\%), y a larga distancia se encuentra la videoconsola (41,7\%). Por el contrario, las nuevas plataformas de televisión no se han asentado todavía en los domicilios; así lo demuestran los bajos índices de posesión de TV por cable (14,1\%), TDT (11,8\%), CSD $(10,2 \%)$ y Canal + $(9,4 \%)$.

Figura 2. Equipamientos en el hogar

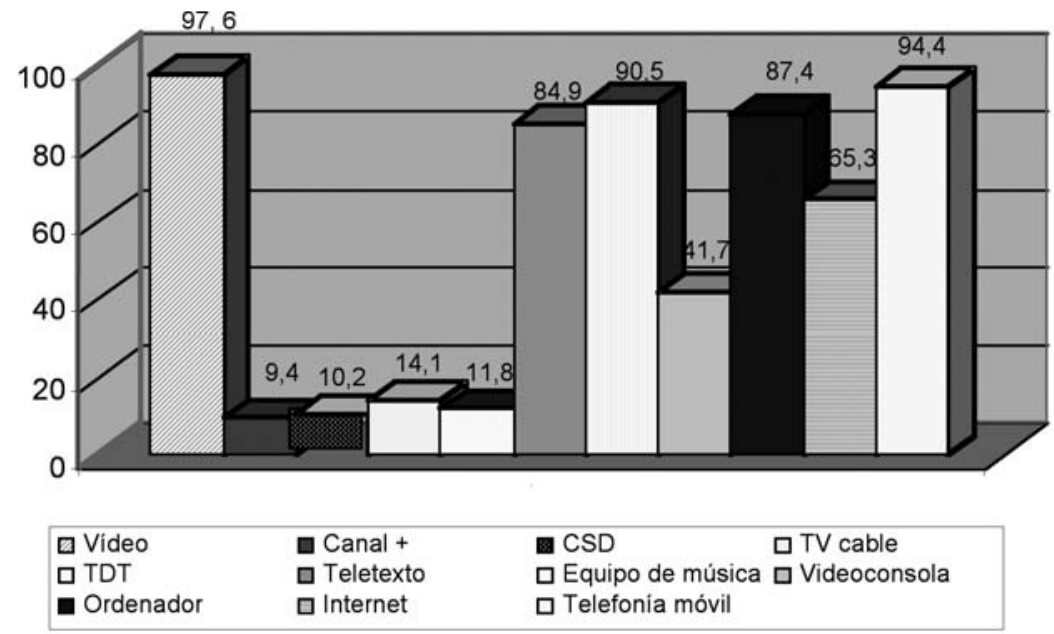

Fuente: Elaboración propia

Si bien el vídeo vuelve a situarse a la cabeza de los equipamientos con los que cuenta el hijo, resulta sorprendente el grado de coincidencia entre el porcentaje de ordenadores en el hogar y el que poseen los más pequeños (un $80,3 \%$ de un $87,4 \%$ ), lo que refleja que son los principales usuarios, al igual que ocurre con la videoconsola (un 33 de un $41,7 \%$ del total). Esta realidad no es extensible al servicio de Internet, que presenta un considerable menor porcentaje (un 43,3 del 65,3\%). La pantalla que deja en desventaja a los hijos es, sin duda, el teléfono móvil (un 33,07 del 94,4\%), un soporte de comunicación mucho más extendido, de momento, entre los adultos. 
Figura 3. Equipamientos que utiliza el hijo

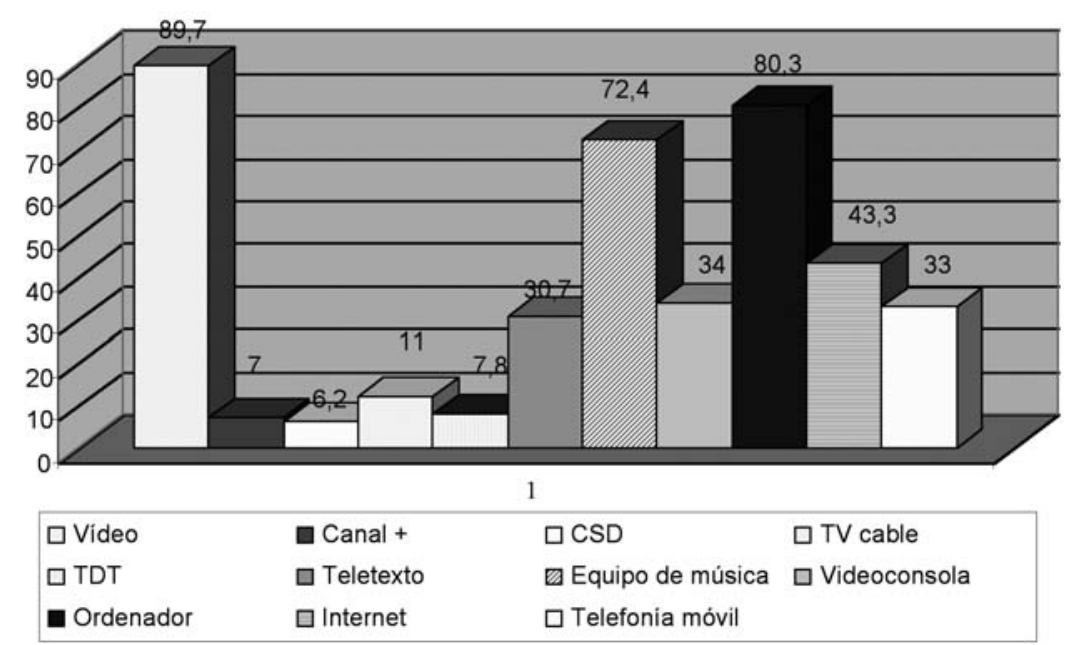

Fuente: Elaboración propia

Figura 4: Comparativa de equipamientos en el hogar y uso del hijo

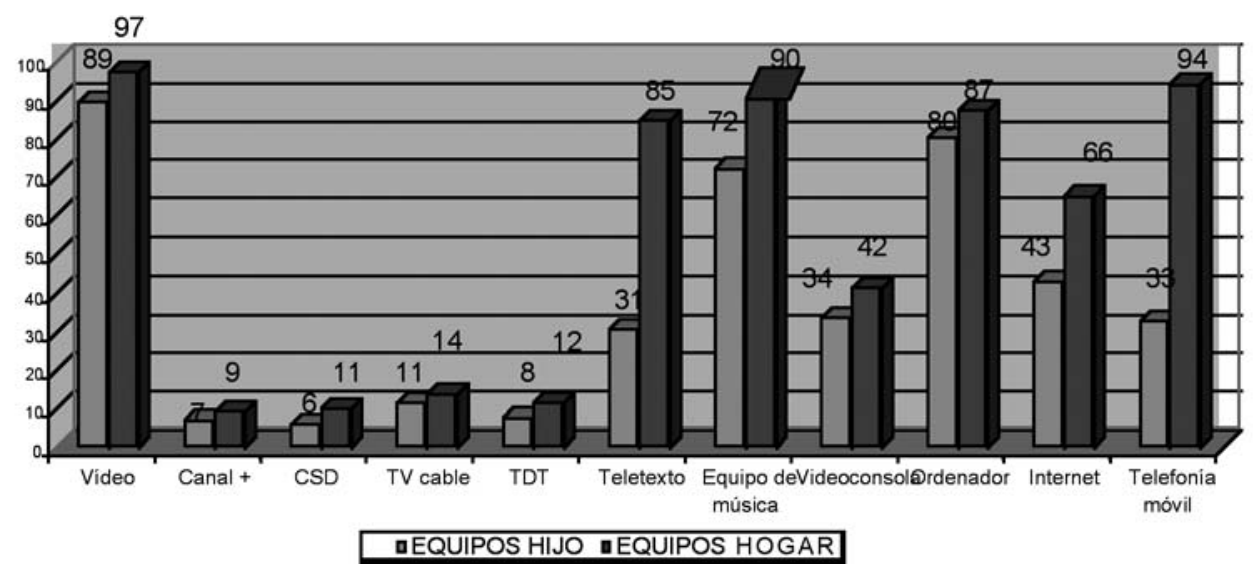

Fuente: Elaboración propia

116 | n 7 | doxa.comunicación 
La media de equipos de televisión en el hogar se sitúa en dos (un 46\% de los encuestados), si bien un 27\% cuentan con un único televisor y un $9 \%$ poseen tres receptores. A esta pantalla hay que sumar la del ordenador, que en la mayoría de los hogares es sólo una (68\%) o dos (19\%). Por otro lado, el porcentaje de quienes no tienen aún este equipo asciende a un $10 \%$ y el de los que cuentan con tres o más de tres es considerablemente más reducido que en el caso de los televisores, como puede observarse en el gráfico comparativo de ambas pantallas.

Figura 5. Número de televisores por hogar

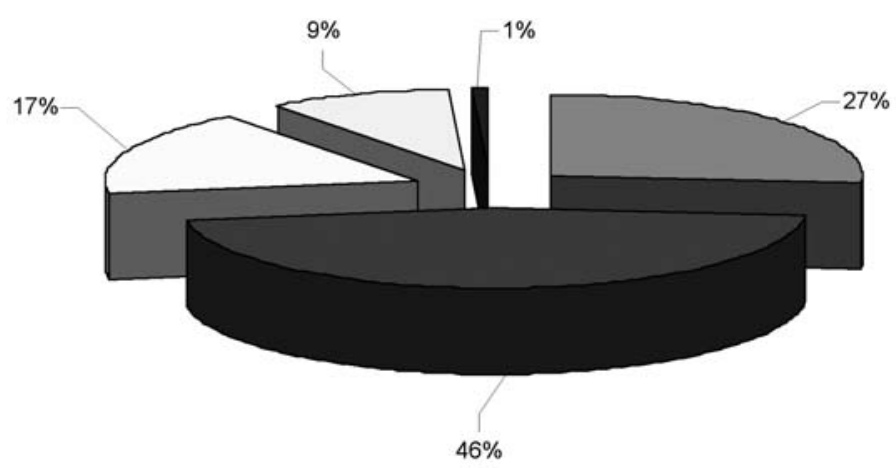

\Uno $\square$ Dos $\square$ Tres $\square$ Más de tres $\square$ Ninguno

Fuente: Elaboración propia

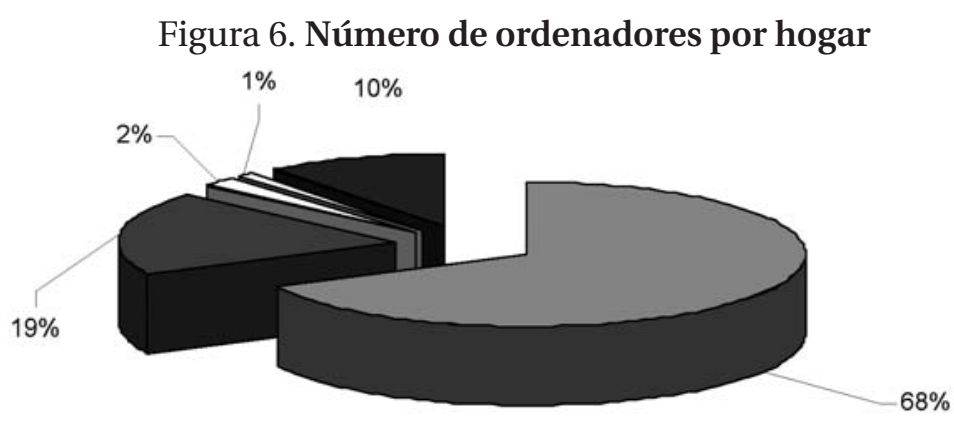

$\square$ Uno $\square$ Dos $\square$ Tres $\square$ Más de tres $\square$ Ninguno

Fuente: Elaboración propia

doxa.comunicación $\left|n^{\circ} 7\right| 117$ 
Figura 7. Comparativa de número de televisores y ordenadores en el hogar

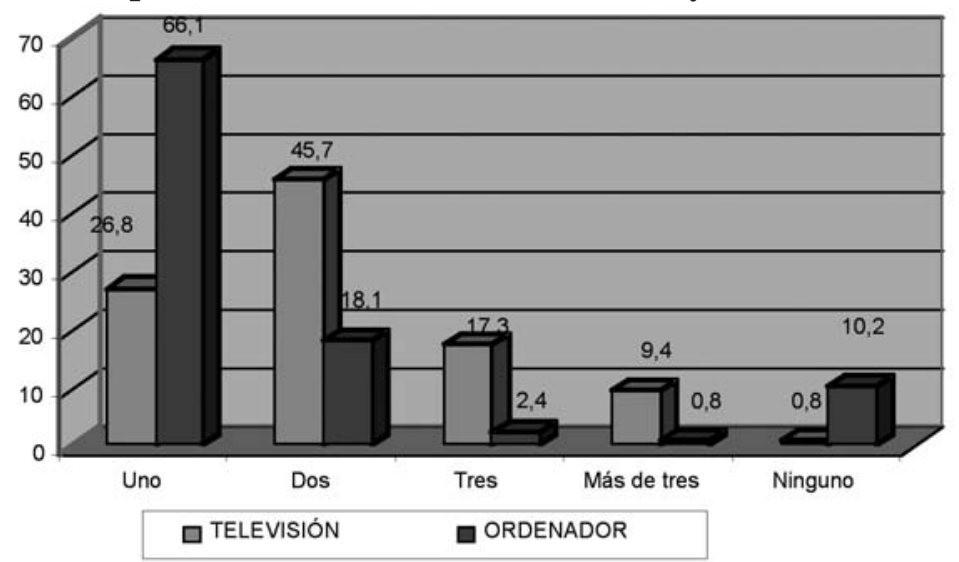

Fuente: Elaboración propia

En cuanto a la ubicación de las pantallas, la televisión sigue ocupando el centro neurálgico del hogar, el salón comedor (un 83,3\%), al contrario que el ordenador, para el que es uno de los lugares menos habituales, con tan sólo un 9,6\%. Donde prepondera su situación es, sin embargo, en la sala de estar $(44,7 \%)$.

Es curiosa la nueva tendencia que se aprecia de pasar a sustituir en el dormitorio de los hijos la televisión (un $14,3 \%$ ) por el ordenador (un 43\%), pantalla que permite el uso añadido de poder ver la programación televisiva.

Figura 8. Comparativa de ubicación del televisor y el ordenador en el hogar

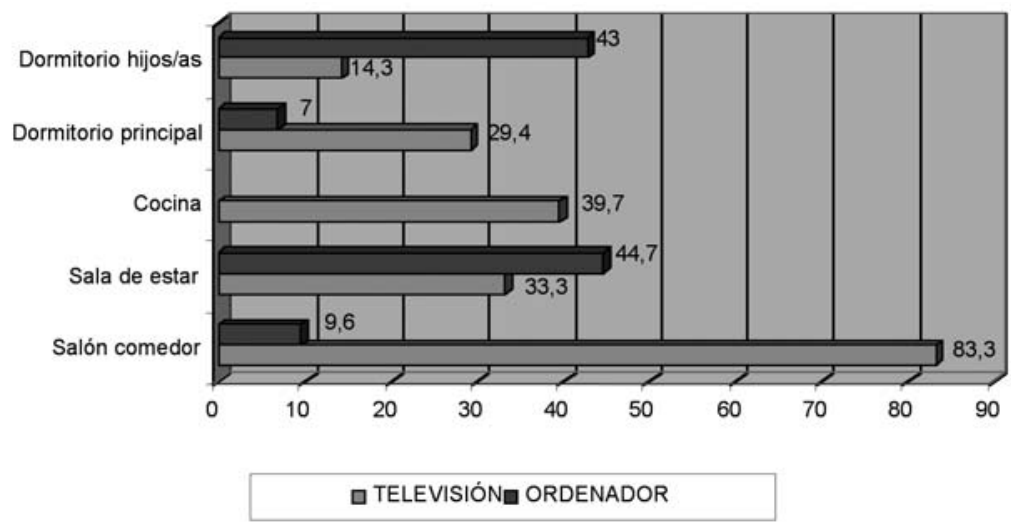

Fuente: Elaboración propia

$118 \mid n^{\circ} 7$ | doxa.comunicación 


\subsection{Comparativa familia e hijos en usos, gratificaciones y hábitos en el consumo multipantallas.}

La mayoría de los representantes de las familias encuestadas afirman ver la televisión entre 2 y 3 horas los días laborables (un 58,2\%), mientras que los fines de semana superan las tres horas de visionado al día (un 61,3\%).

\section{Figura 9. Reparto del consumo de televisión en familia}

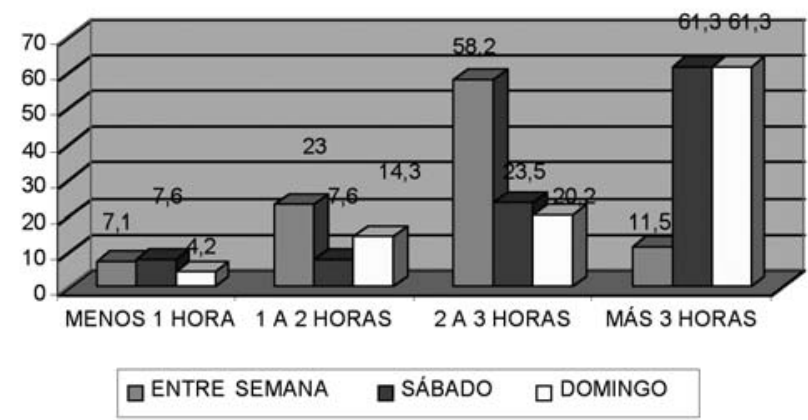

Fuente: Elaboración propia

El consumo de los hijos es, en proporción, bastante más reducido que el del total de la familia, situándose de lunes a viernes entre 1 y 2 horas (un 45,1\%); los sábados y domingos, aunque alcanza cifras considerables (son $47,5 \%$ y 43,7\%, respectivamente, los que ven más de tres horas), el consumo se reparte en mayor medida entre quienes ven de 1 a 2 horas o entre 2 y 3, como puede evidenciarse en el siguiente gráfico.

Figura10. Reparto del consumo de televisión por los hijos

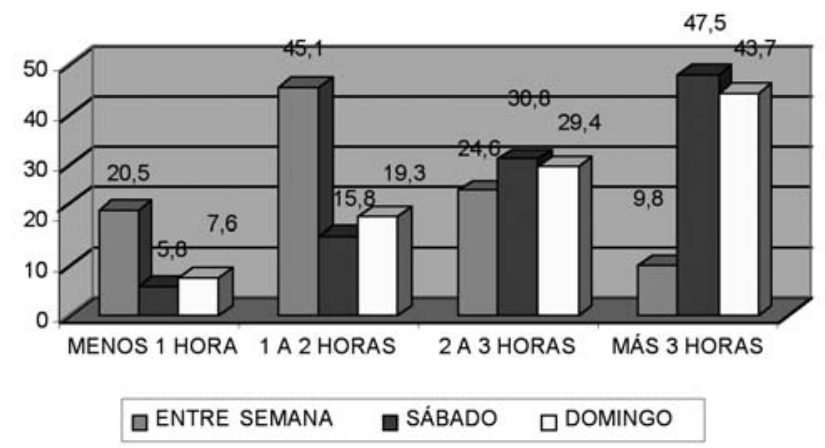

Fuente: Elaboración propia 
En el caso del ordenador, se aprecia una diferencia considerable respecto a la televisión en el número de horas que tanto el conjunto de miembros de la familia como los hijos pasan al día frente a la pantalla. La mayor parte sólo llegan a alcanzar una hora de consumo, con similares cifras los días lectivos y los festivos.

Figura 11. Reparto del consumo del ordenador por la familia

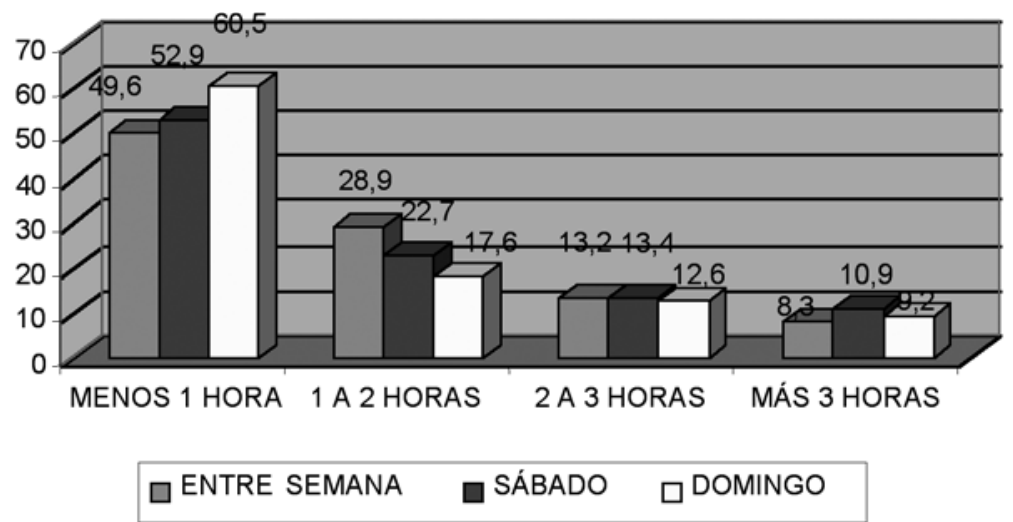

Fuente: Elaboración propia

La tendencia en el reparto de tiempo que pasan delante del ordenador los hijos es semejante a la del total de la familia.

Figura 12. Reparto del consumo del ordenador por los hijos

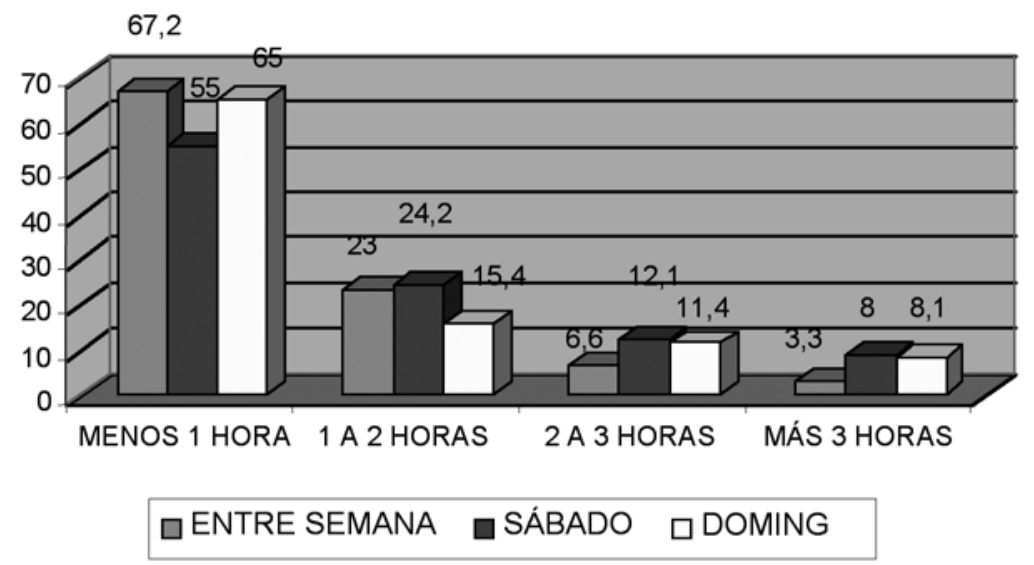

Fuente: Elaboración propia

$120 \mid n^{\circ} 7$ doxa.comunicación 
Los padres prefieren ver televisión principalmente los sábados (un 57,3\%), en franja prime time, de 20 a 24 horas (un $63 \%$, como primera opción) y en horario de sobremesa y tarde, como segunda y tercera preferencia, con un $37,4 \%$ y $31,3 \%$, respectivamente. Las franjas menos concurridas en cuanto a demanda son la madrugada y la mañana.

Figura 13. Televisión: preferencias de consumo de los padres

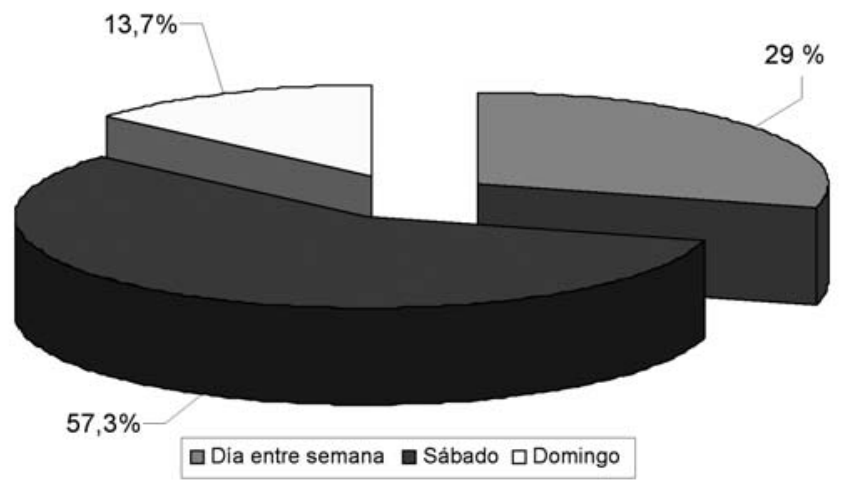

Fuente: Elaboración propia

Gráfico 14. Televisión: horarios preferidos por los padres

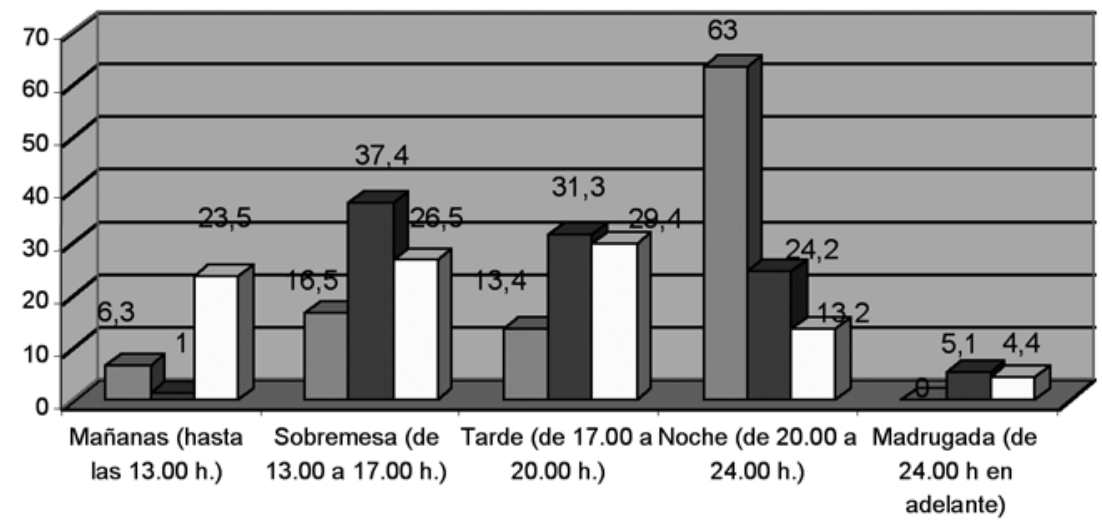

$1^{\mathrm{a}}$ preferencia $\square 2^{\mathrm{a}}$ preferencia $\square 3^{\mathrm{a}}$ preferencia

Fuente: Elaboración propia 
Los formatos favoritos que seleccionan los padres son los informativos $(46,4 \%)$, seguidos de las películas $(21,6 \%)$, las series (12\%) y los divulgativos y documentales $(7,2 \%)$. Sin embargo, y a diferencia de los datos que ofrecen los estudios reales de audiencia, indican que los que menos les gustan son los reality shows, los programas del corazón y los musicales, reduciéndose a un $0,8 \%$ el porcentaje en cada uno de los casos.

\section{Figura 15. Televisión: programación que prefieren los padres}

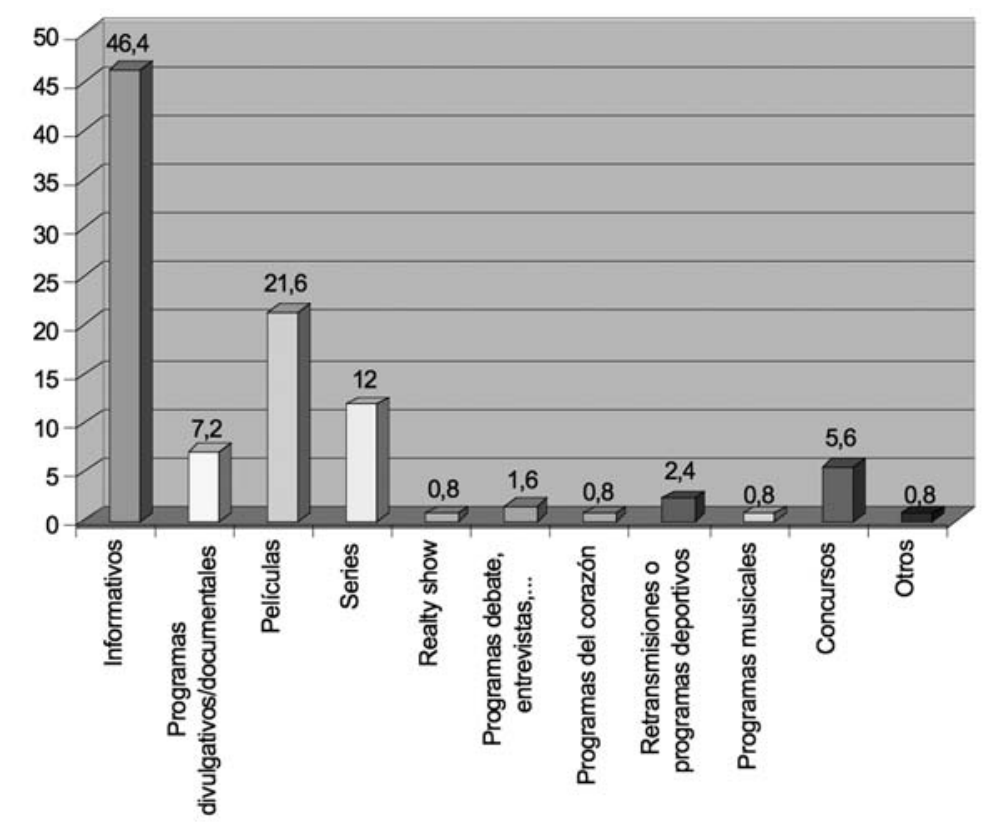

Fuente: Elaboración propia

La mayor parte de los padres, un 41,7\%, afirma que suele ver la televisión en familia, aunque un 37\% señala que solo con su pareja y un 18,9\% afirma que en solitario. Esta última cifra es preocupante, ya que refleja lo poco acompañados que están esos niños por sus padres cuando ven televisión. 
Figura 16. Cómo ven la televisión los padres

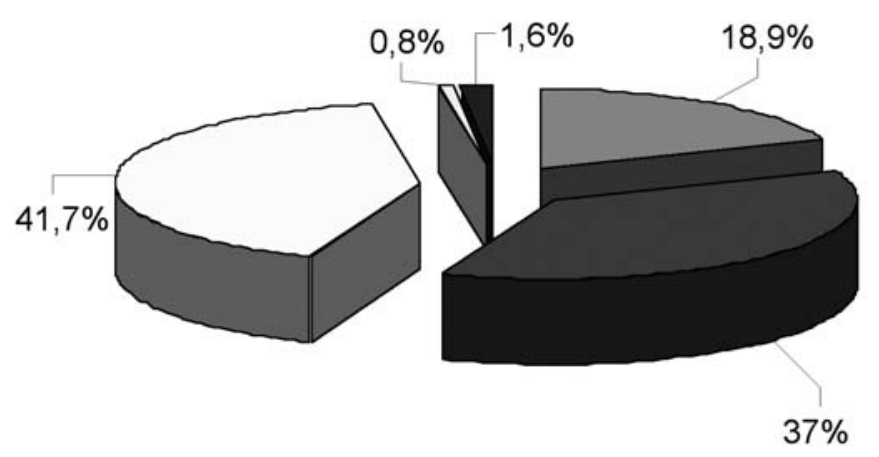

$\square$ Sólo/a $\square$ Con su pareja $\square$ En familia/ con sus hijos $\square$ Con otras personas $\square \mathrm{Ns} / \mathrm{Nc}$

Fuente: Elaboración propia

Los padres suelen preseleccionar el espacio televisivo que van a ver, así lo hace un $67,7 \%$ de los encuestados; aunque un considerable $13,4 \%$ asume que se sienta delante de la pantalla de televisión, de manera indiscriminada, para ver "cualquier cosa".

Figura 17. Motivos por los que los padres ven la televisión

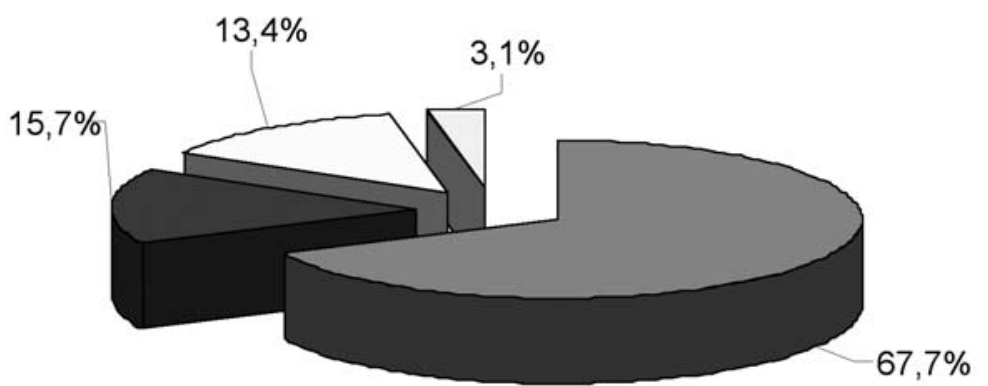

$\square$ Le interesa ver un programa concreto que sabe que se emite

arograma que le pueda interesar sin saber que se

Para ver cualquier cosa

$\square \mathrm{Ns} / \mathrm{Nc}$

Fuente: Elaboración propia 


\section{Conclusiones}

1. La televisión sigue siendo la pantalla protagonista en el consumo doméstico familiar, ocupando el centro neurálgico del hogar. La preponderancia del televisor se produce en el número de aparatos y en el espacio familiar "estelar", que se le destina (salón comedor).

2. Las nuevas plataformas de televisión (cable, satélite, TDT) no se han asentado todavía en los domicilios, sigue prevaleciendo el reinado de la televisión en abierto.

3. Los hijos son los principales usuarios de las pantallas de videoconsolas y ordenadores en el hogar; mientras que son los padres quienes controlan "el mando a distancia".

4. Los informativos son el género televisivo preferido por los padres, lo que dificulta que compartan el consumo audiovisual con sus hijos, dado que estos tienen otro tipo de preferencias, basadas en la ficción y entretenimiento.

5. Apenas la mitad de los padres sensibilizados en consumo audiovisual ven la televisión en familia. Sin embargo, suelen preseleccionar el espacio televisivo que van a consumir, de manera discriminada.

\section{Referencias bibliográficas}

Elizalde, L: (2007): “El papel de la familia nuclear en la recepción infantil”, TELOS, Cuadernos de Comunicación, Tecnología y Sociedad, vol. 73, pp. 71-73.

Gabelas Barroso, J. A. y Marta Lazo, C. (2008): Consumos y mediaciones de familias y pantallas. Nuevos modelos y propuestas de convivencia, Zaragoza: Departamento de Salud y Consumo del Gobierno de Aragón.

Gabelas Barroso, J. A. (2005): “Televisión y adolescentes: una controvertida y polémica relación”, Comunicar, Revista Científica Iberoamericana de Comunicación y Educación, vol. 25, Huelva, pp. 137-146.

Gabelas Barroso, J. A. (2007): Crecer entre pantallas. Seminario Pantallas Sanas. TIC, salud y vida cotidiana, Zaragoza: Gobierno de Aragón.

Lazzarini, B. (2006): Salud y calidad de vida. UNESCO de Sostenibilitat. Universitat Politécnica de Catalunya. Disponible en Internet [URL] http://portalsostenibilidad.upc.edu/detall_01.php?numapartat=6\&id=76, consultado el 8 de enero de 2007.

Marta Lazo, C. (2005): La televisión en la mirada de los niños, Madrid: Fragua.

Marta Lazo, C y Gabelas Barroso, J. A. (2007): “La educación para el consumo de pantallas, como praxis holística”, Revista Latina de Comunicación Social, vol. 62. Disponible en Internet [URL] http://www.ull.es/publicaciones/latina/200720, consultado el 9 de diciembre de 2007. 
Carmen Marta Lazo y José Antonio Gabelas Barroso

Pérez Ornia, J.R. y Núñez Ladevéze, L. (2003): “Programación infantil en la televisión española: Inadecuada relación entre oferta y demanda”, TELOS, Cuadernos de Comunicación, Tecnología y Sociedad, vol. 54 segunda época, pp. 103-113.

Requena González, J. (1988): El discurso televisivo: espectáculo de la posmodernidad, Madrid: Ediciones Cátedra. Spectus (2004): Máscaras y espejismos: una aproximación al impacto mediático, Madrid: Ediciones de la Torre.

Trejo Delarbre, R. (2006): Viviendo en el Aleph. La sociedad de la información y sus laberintos, Barcelona: Gedisa. 
